\title{
Tecnologia Móvel na Gestão de Atividades Turísticas em Aracaju, SE, Brasil
}

\author{
Leylane Meneses Martins ${ }^{a}$ \\ José Wellington Carvalho Vilar ${ }^{b}$ \\ Rosangela Vilela Sobral Silvac \\ Marcélio de Oliveira Santana ${ }^{d}$
}

\section{Resumo}

O objetivo deste estudo é discutir a influência crescente das tecnologias móveis na gestão das empresas de turismo, tendo como referência empírica as perspectivas de gestores públicos e fornecedores turísticos da cidade de Aracaju, capital do estado de Sergipe, Brasil. A tecnologia modifica a sociedade e consequentemente a sua economia. $\mathrm{Na}$ relação com o turismo, possui a importância de oportunizar o avanço da destinação por meio da promoção e comercialização, encurtar distâncias e catalisar o conhecimento de forma rápida e competitiva. Mediante revisão de literatura acerca das temáticas "gestão e governança turística", "tecnologia" e "tecnologia móvel", deu-se o processo da coleta de dados por meio de um formulário específico com cinco perguntas objetivas para gestores públicos e prestadores de serviços do turismo, visando avaliar a intervenção das tecnologias móveis na governança e gestão da atividade de cada empresa. Participaram da pesquisa de campo cinco grupos de prestadores de serviços do turismo de Aracaju: meios de hospedagens, agências de viagens, locadoras de veículos e gestão pública estadual e municipal. A análise estatística das respostas ao formulário permitiu concluir que o uso da tecnologia móvel ocasiona transformações na governança e gestão do turismo, sendo assim uma ferramenta intermediária e relevante que facilita e agiliza as tomadas de decisões e estratégias de atuação para aproximar o turista dos produtos e serviços turísticos, além de resolver necessidades pessoais e empresariais do dia a dia.

Palavras-chave: Governança turística; Tecnologia; Tecnologia móvel; Aracaju/SE.

\section{Abstract}

Mobile technology in the management of tourist activities in Aracaju, SE, Brazil

This study discusses the increasing influence of mobile technologies in the management of tourism companies by public managers and tourism suppliers' perspectives in Aracaju, capital of the state of Sergipe. Technology has modified society and, consequently, its economy. In the tourist field, it has improved the potential of destinations through promotion and marketing, shortened distances, and catalyzed knowledge in a fast and competitive way. The literature review is constituted of subjects such as tourism management, governance, and mobile technology. In this context, the data collection process was conducted by means of a specific form with five objective questions applied to public managers and tourist service providers in order to evaluate the intervention of mobile technologies in the company's governance and management. Five tourism provider groups from Aracaju constitute the field research: lodging facilities, travel

a. Mestre em Turismo pelo Instituto Federal de Sergipe (IFS), Aracaju, SE, Brasil. E-mail: leylaneturismo@yahoo.com.br

b. Doutor em Análisis Geográfico en la Ordenación del Teritorio pela Universidade de Granada, Granada, Espanha. Docente do Instituto Federal de Sergipe (IFS), Aracaju, SE, Brasil. E-mail: wvilar@yahoo.com.br

c. Mestre em Turismo pelo Instituto Federal de Sergipe - IFS, Aracaju, SE, Brasil. E-mail: rosangelaavilela@gmail.com

d. Tecnólogo em Gestão de Tecnologia da Informação pela Faculdade de Administração e Negócios de Sergipe - FANESE, Aracaju, SE, Brasil. E-mail: marcelio911@gmail.com 
agencies, car rental companies, and state and municipal management. Statistical analysis showed that the use of mobile technology leads to transformations in tourism governance and management, thus being a relevant tool that facilitates, intermediates and accelerates decision-making and the strategy process, hence bringing tourists closer to the tourist offer, as well as solving everyday business needs.

Keywords: Tourism governance; Technology; Mobile technology; Aracaju/SE.

\section{Resumen}

Tecnología móvil en la gestión de actividades turísticas en Aracaju, SE, Brasil

El objetivo de este estudio es discutir la influencia creciente de las tecnologías móviles en la gestión de las compañías de turismo, teniendo como referencia empírica las perspectivas de gestores públicos y proveedores turísticos de la ciudad de Aracaju, capital de Sergipe (Brasil). La tecnología modifica la sociedad y, consecuentemente, su economía. En la relación con el turismo, es importante por posibilitar el avance del destino por medio de la promoción y comercialización, acortar distancias y catalizar el conocimiento de forma rápida y competitiva. A partir de la revisión de literatura acerca de las temáticas "gestión y gobernanza turística", "tecnología" y "tecnología móvil", se realizó el proceso de la recolección de datos por medio de un formulario específico con cinco preguntas objetivas a gestores públicos y a prestadores de servicios del turismo para evaluar la intervención de las tecnologías móviles en la gobernanza y gestión de la actividad de cada compañía. Participaron en la investigación de campo cinco grupos de prestadores de servicios del turismo de Aracaju: medios de hospedaje, agencias de viajes, arrendadoras de vehículos y gestión pública estadual y municipal. El análisis estadístico de las respuestas al formulario permitió concluir que el uso de la tecnología móvil ocasiona transformaciones en la gobernanza y la gestión del turismo, siendo una herramienta intermedia y relevante que facilita y agiliza las tomas de decisiones y las estrategias para acercar los productos y servicios turísticos al turista, además de resolver necesidades personales y empresariales cotidianas.

Palabras clave: Gobernanza turística; Tecnología; Tecnología móvil; Aracaju/SE.

\section{INTRODUÇÃO}

A mobilidade aponta novos paradigmas e muda comportamentos humanos. A sociedade está progressivamente envolvida nas facilidades e possibilidades de acesso a informações em qualquer momento e local. Com essa mudança de postura, profissionais de várias áreas têm a necessidade e urgência de adequação e capacitação para atender o novo cliente.

Sabe-se que a velocidade das mudanças ocorridas pela tecnologia, tanto no âmbito global como no social, tem um poder inovador e transformador. Assim, a tecnologia muda a sociedade e consequentemente a sua economia (Hassan, 2011). Vive-se hoje a era tecnológica, responsável por grandes mudanças que resultam em repercussões significativas na produção e gestão das empresas, com novos formatos, perfis, técnicas e estruturas hierárquicas, com mais agilidade, rapidez e menos custos.

A relação da tecnologia com o turismo abre a oportunidade de avanços na destinação e os impactos ocasionados pelo uso da tecnologia e da inovação nas empresas e na sociedade - como encurtamento de distâncias através da internet, catalisação do conhecimento de forma rápida e competitiva, dentre outros fatores - tornam-se incalculáveis, podendo trazer retornos positivos por meio da promoção e comercialização para praticamente todas as partes do mundo. 
Assim, o turismo tenta se moldar à nova era digital para manter a sua competitividade nas destinações, o que envolve a prestação de serviços passível a mudanças tecnológicas que viabilizem meios mais rápidos para atrair a demanda, com fomento à competitividade e à globalização (Tan, Lee, Lin, \& Ooi, 2017).

0 avanço tecnológico trouxe o uso intenso, na vida pessoal e profissional, de tecnologias móveis (smartphones, tablets, notebooks, GPS) para auxiliar nas atividades do dia a dia. $\mathrm{O}$ advento do smartphone veio revolucionar e modificar a sociedade com a oferta de inúmeros recursos reunidos em um único aparelho, além de disponibilizar funcionalidades por meio de um conjunto de aplicativos (apps) que facilitam o acesso à informação, a fim de oferecer atividades específicas, tanto para a solução do aumento de produtividade na empresa como para um serviço de entretenimento (Hoehle \& Venkatesh, 2015). 0 propósito dos apps é facilitar a vida dos usuários e oportunizar acesso direto, muitas vezes gratuito, a vários serviços.

Diante desse cenário, emerge uma questão: qual a influência das tecnologias móveis na condução da gestão das empresas de negócios turísticos? Para respondê-la, planejou-se o presente artigo, com objetivo geral de discutir a influência crescente das tecnologias móveis na gestão das empresas do setor do turismo, tendo como referência empírica as perspectivas de gestores públicos e fornecedores turísticos da cidade de Aracaju, capital do estado de Sergipe, Brasil. Por meio deste estudo será discutido o uso da tecnologia móvel como ferramenta de produtividade e de valor adicional, associada ao processo de gestão e inovação das atividades das empresas prestadoras de serviços turísticos.

Além da Introdução e das Considerações finais, o estudo apresenta três momentos: revisão de literatura acerca das temáticas "gestão", "governança", "tecnologia" e "tecnologia móvel"; pesquisa de campo por meio de aplicação de formulários a gestores públicos e prestadores de serviços turísticos de Aracaju; e, por último, resultados e discussão.

A principal justificativa para a escolha do objeto de estudo aqui proposto se dá em função da sua projeção inovadora para o turismo e a partir da constatação das discussões ainda incipientes sobre a intervenção das tecnologias móveis na gestão de produtos, serviços e/ou destinos turísticos.

Ademais, a importância do tema está associada à possibilidade de fomentar estudos voltados para tecnologias móveis em função dos interesses do turismo na era digital e tecnológica, para que suas ações sejam planejadas, ordenadas e inovadoras, visto que se trata de uma vantagem competitiva acompanhar o ritmo da tecnologia, além de ser uma oportunidade eficiente de impulsionar a divulgação das atividades de gestores e prestadores de serviços do turismo em virtude da repercussão positiva de sua gestão.

\section{REVISÃo DE LITERATURA}

As transformações advindas da tecnologia mantêm-se em alta velocidade, com remodelagem de padrões, comportamentos e avanços cada vez maiores nos níveis de competitividade das destinações turísticas. Nesse cenário, o turismo deve oferecer a mais adequada infraestrutura com prestação de serviço e atrativos inovadores e diversificados. Para esse fim, é fundamental entender o desempenho da gestão pública e privada, bem como das empresas prestadoras de serviços turísticos, principalmente dos agentes que deverão qualificar e garantir o êxito do turismo. 
Para acompanhar a mudança de paradigmas, a gestão pública do turismo apresenta um avanço em sua forma de governança, na busca por compartilhar responsabilidades, bens e objetivos e incluir em sua gestão a participação da iniciativa privada, formada em sua maioria por prestadores de serviço nas áreas de agências de viagens, meios de hospedagem, locadora de veículos, bares e restaurantes entre outros. Cooper, Hall e Trigo (2011) relatam que

em países desenvolvidos, muitas das atividades promovidas pelo Estado que visam ao bem-estar social, incluindo-se a administração do lazer e das instalações culturais, são agora operadas e implementadas por empresas do setor privado ou por organizações não governamentais. Portanto, ao invés de a implementação de políticas governamentais ser realizada por uma única agência governamental, o que se observa hoje é uma ênfase maior em parcerias. (p. 78)

A governança é um novo modelo político que adota ferramentas mais plurais para governar, ao incluir a comunidade local como protagonista junto com a iniciativa privada nas tomadas de decisões. Igualmente, a governança aponta relações com base na confiabilidade, reciprocidade, transparência e lealdade com interdependência entre os agentes (Rhodes, 1996; Trentin, 2016).

É importante ressaltar que gestão e governança são termos com finalidades diferentes (Brito, 2014; Roth, Wegner, Antunes, \& Padula, 2012), porém as diferenças não são tão fáceis de perceber na prática do cotidiano profissional.

A governança encarrega-se da definição da estrutura da rede, do detalhamento de sua organização, da instituição de mecanismos regulatórios e do processo de tomada de decisão, enquanto a gestão se encarrega de planejar, executar e controlar as estratégias e ações, dentro dos limites estabelecidos pela governança. (Roth et al., 2012, p. 120)

A responsabilidade da governança requer autonomia para estabelecer normas, padrões, regulamentos e medidas de funcionamento junto a um grupo de gestores. A gestão tem o papel da prática gerencial, com liberdade para usar conhecimentos e habilidades no controle e avaliação contínuos para atingir os objetivos coletivos.

De acordo com Pedroso (2012), a gestão é uma função também social, com objetivo de tornar as pessoas capazes de realizar atuação conjunta, mesmo de forma independente em cada empresa, mas com propósitos comuns. Nesse caso, gestores públicos e prestadores de serviços do turismo, reunidos, buscam a formação e desenvolvimento do setor.

Beritelli e Bieger (2014) afirmam que, de forma estrutural, a governança associada à gestão põe em prática processos e mecanismos que ajudam a resolver como e por que fazer as atividades através das relações e objetivos comuns.

Mediante relações de liderança e interação com o mercado do turismo, deve existir participação mútua na elaboração de planos e ações que resultarão no caminho crescente desejado, com a geração de melhorias na eficiência e eficácia do sistema de gestão de cada empresa do turismo e para a destinação como um todo (Baggio, Scott, \& Cooper, 2010).

No turismo, a governança deve imperar de forma descentralizada, participativa e transparente nas relações público-privadas para o sucesso do planejamento e gestão turística (Svensson, Nordin, \& Flagestad, 2005). 
A governança turística pode ser desenvolvida em várias esferas socioeconômicas, ambientais e políticas, através das parcerias que envolvem a iniciativa privada e o poder público para dar andamento às ações que superam as atividades individuais, com desempenho de um papel de organização, mutualidade e gestão em prol do turismo (Tomio \& Schmidt, 2014).

Segundo González (2014), a governança turística deve ser representada a partir dos seguintes fatores: ligação com as novas formas de atuação do governo para uma gestão bem-sucedida; cooperação e relações de interação entre atores sociais para encarar os desafios de aumentar a competitividade de um destino ou setor; protagonismo da estrutura institucional pública no início do processo de parcerias e diálogos com demais agentes sociais; orientação para traçar, selecionar e coordenar objetivos específicos através de técnicas coletivas.

Na sua operacionalidade, a governança turística estipula procedimentos que permitam um trabalho conjunto entre vários agentes sociais com processos de gestão e desenvolvimento público e coletivo, tendo como ferramentas a inovação e a tecnologia, pois "muito mais do que máquinas, sistemas e dispositivos ligados entre si, a tecnologia envolve desde o surgimento da ideia até a concretização e a entrega do produto ou serviço, passando principalmente pelas pessoas" (Bolsoni, 2004, p. 98).

A tecnologia é formada por um conjunto de ferramentas, técnicas e processos que, de forma rápida, auxiliam e transformam a contínua evolução da sociedade. No turismo, ela propicia diversas mudanças que atingem diretamente tanto os destinos emissores quanto os receptores, principalmente quanto à rapidez das informações e aos tipos de serviços e produtos oferecidos com objetivo de incrementar e inovar a atividade. Nesse sentido, é fundamental

compreender o fenômeno de turismo que envolve também compreender a dinâmica da inovação tecnológica neste setor, sobretudo porque a disponibilidade de novas tecnologias levou ao desenvolvimento de novas competências, novos materiais, novos serviços, novos negócios, novas formas de organização, e a uma reconfiguração do trabalho. (Martins, Fiates, \& Pinto, 2016, p. 69)

A tecnologia traz consigo inovação e transformação e requer da sociedade agilidade e expertise para acompanhar as novas formas de produção, comunicação, planejamento e gestão. A inserção do turismo nesse ritmo é importante para modernizar e oferecer seus produtos e serviços para o novo mercado (Hassan, 2011). A tecnologia muda a sociedade e consequentemente a economia e, em sua relação com o turismo, passou de uma ferramenta de marketing para um instrumento de criação de conhecimento. Vale destacar que as tecnologias vêm e vão, e sempre haverá inovações e avanços a serem realizados (Xiang, 2017).

O uso da tecnologia, além ser um instrumento de apoio para o turismo, está inserido na sua forma de trabalho, resultando em novas possibilidades de vantagem competitiva e numa função importante no desenvolvimento turístico. Isso porque acarreta uma mudança significativa no contexto mundial, possibilitando a distribuição da informação e grande exposição de localidades para todos, a fim de propiciar maior competitividade entre destinos e instigar a melhoria nos serviços oferecidos, valorizando a criatividade, a inovação e a singularidade de cada atrativo e/ou produto turístico (Nascimento, Maia, \& Dias, 2012). 
A tecnologia age como mecanismo para aumentar a eficiência das empresas, reduzir custos e aprimorar serviços, além de proporcionar novas possibilidades de crescimento, assim como desafios a serem enfrentados em busca de vantagem competitiva (Martins et al., 2016). E, como a principal atividade do turismo é a oferta de serviços, ele está suscetível às transformações tecnológicas para criação de formas diferentes e inovadoras de atender às demandas e acompanhar o mercado competitivo (Hassan, 2011). Buhalis (1998) escreveu em seus estudos sobre as mudanças que o uso das tecnologias ocasiona no desenvolvimento do turismo:

Inevitavelmente, o turismo também é afetado pela revolução tecnológica. Tanto os destinos turísticos como as empresas precisam cada vez mais adotar métodos inovadores para aumentar sua competitividade. Do lado da demanda, o consumidor novo, sofisticado, experiente e exigente, se torna cada vez mais familiarizado com as tecnologias emergentes e requer produtos flexíveis, especializados, acessíveis, interativos e comunicação com os gestores do destino. Desse modo, emergem novas práticas de gestão, aproveitando a revolução para reestruturar todos os processos de negócios do turismo. (p. 409, tradução nossa)

De maneira geral, a revolução tecnológica proporciona muitas mudanças na gestão do turismo - principalmente no planejamento, comercialização, promoção e coordenação das atividades da oferta do serviço -, para assim acompanhar a rápida evolução da demanda e ter vantagem competitiva no mercado.

Organizações com padrões inertes têm uma gestão limitada e arcam com a perda de posição no mercado. Para uma empresa permanecer com vantagem competitiva no mercado, faz-se necessário ser sensível às mudanças capazes de enfrentar a dinamicidade da globalização. E estas mudanças devem vir atreladas à aplicação de estratégias tecnológicas, ou seja, utilizar a tecnologia com fins competitivos através de recursos que forneçam os melhores produtos e serviços ao mercado (Ramos, Mendes Filho, \& Lobianco, 2017).

0 setor de turismo recorre ao uso da tecnologia em muitos segmentos. Em suas práticas, as mudanças são fundamentais para o desenvolvimento de novos produtos, qualificação dos recursos humanos, facilidade da comunicação, melhora das experiências de viagens nos produtos e serviços, e na personalização da prestação de serviços (Hassan, 2011).

Para satisfazer a demanda turística e sobreviver a longo prazo, não há escolha senão associar tecnologia à oferta e melhorar a interatividade com o mercado (Buhalis, 1998). As empresas que implementam novas tecnologias têm possibilidade de enfrentar novos concorrentes, pois, devido aos avanços e melhorias, criam diferentes formas de relação entre produtores, fornecedores e clientes, e maneiras de comercialização do seu produto ou serviço.

\section{A TECNOLOgIA MÓVEL NO TURISMO}

De acordo com Ramos et al. (2017), é perceptível o crescimento na geração de novas tecnologias para celulares, anteriormente usados somente para fazer ligações, mas que hoje servem como ferramenta de trabalho, comunicação via satélite (GPS), redes locais sem fio, entre outras utilidades. 
A funcionalidade do telefone celular tradicional durante a última década foi usada principalmente para recursos de chamada e texto, devido às suas capacidades tecnológicas limitadas. Desde o surgimento de telefones inteligentes (smartphones) e do avanço das redes de dados sem fio (3G, 4G e wireless), com evolução de longo prazo da terceira geração e agora da quarta, é sempre possível o desenvolvimento de novos softwares. (Tan et al., 2017, p. 560, tradução nossa)

Hoje em dia os celulares estão cada vez mais acessíveis, gerando o fenômeno intitulado mobile computing (computação móvel) (Ramos et al., 2017), isto é, as pessoas possuem um smartphone com diversas funcionalidades para uso em qualquer lugar. Os benefícios dos "sempre conectados", "sempre com você", e a facilidade de uso, independente do lugar, ajudam a promover a eficiência nas tarefas diárias dos usuários (Tan et al., 2017).

A utilização de smartphone e tablets é uma atividade comum no dia a dia das pessoas, mais da metade da população mundial possui um desses aparelhos. Por possuírem sistema operacional (plataforma que permite desenvolver, instalar e executar aplicativos), os dispositivos móveis se parecem com um computador de mão. 0 mercado corporativo tem percebido que investir em aplicações móveis proporciona significativos resultados para agilizar seus negócios e potencializa seus lucros. (Ramos et al., 2017, pp. 133-134)

Com o avanço da tecnologia, os celulares passaram a ser telefones inteligentes (smartphones), oferecendo recursos muito úteis reunidos em um único aparelho, além de disponibilizar funcionalidades por meio de inúmeros aplicativos que facilitam a rapidez no acesso à informação e à resolução de situações profissionais e pessoais.

Os tablets são aparelhos semelhantes a computadores, porém com a praticidade de serem portáteis e terem o mesmo sistema operacional que os smartphones, sendo utilizados em muitas empresas, inclusive no turismo, caracterizados como uma ferramenta de trabalho de muitos gestores. Na visão de várias empresas, a tecnologia móvel, através de smartphones e tablets, deve gerar lucros, diminuir custos e aumentar a vantagem competitiva perante o mercado (Rivera, Croes, \& Zhong, 2016).

O mercado corporativo busca acompanhar a evolução tecnológica através do uso de aplicativos móveis nas atividades da empresa. 0 propósito é inovar seus serviços com tecnologia, eficiência e agilidade, incorporando as aplicações móveis com seus sistemas de trabalho (Ramos et al., 2017).

Os órgãos governamentais começaram a usar aplicativos móveis para comunicação de forma estratégica, para divulgar ações para a sociedade. As empresas privadas já aderiram a essa tendência tecnológica há mais tempo, visando à comercialização, à negociação e ao planejamento (Noor, Mahmud, Wahidin, \& Arshad, 2017).

As mudanças e avanços gerados pelo crescimento da tecnologia na área do turismo impulsionam a criação de novas maneiras e meios de criar, transformar e difundir produtos e serviços turísticos através da interconectividade entre pessoas, associada ou não à internet. Esses avanços correspondem à criação de diversos aplicativos de dispositivos móveis para auxiliar os envolvidos com o turismo, para a oferta e/ou para demanda turística (prestadores de serviços turísticos e/ou turistas).

No turismo, a elaboração e a utilização de aplicativos móveis podem ajudar um destino no planejamento, gestão e promoção de marketing, além de proporcionar 
facilidades de informações, aproximação e escolhas ao destino (Rivera et al., 2016). Levando-se em consideração o olhar do turista, o papel da tecnologia evoluiu na sua aplicabilidade como um meio de comunicação e convencimento on-line, que auxilia nas necessidades e desejos (Xiang, 2017).

Nos últimos anos, a tecnologia do celular evoluiu consideravelmente, com dispositivos e sistemas operacionais fornecidos principalmente pelas empresas Apple, Google e Microsoft, cada vez mais aprimorados. Esses avanços vieram acompanhados de aplicativos móveis para facilitar o uso de sistemas convencionais que antes só era possível no acesso pelo computador (Hoehle \& Venkatesh, 2015).

Aplicativos móveis são softwares desenvolvidos de acordo com o usuário final, elaborados através de um sistema operacional para dispositivo móvel (celular) com objetivo de melhorar as utilidades ao proporcionar que os usuários realizem tarefas específicas (Dickinson et al., 2014; Tan et al., 2017).

Os aplicativos existem devido ao avanço da tecnologia para os aparelhos móveis (celulares), tendo se tornado uma nova marca para o avanço da metodologia experimental e operacional no campo mobile, com a função de recurso de trabalho e execução de atividades que podem fornecer material de pesquisa, respostas e solicitações a um grande grupo de participantes em tempo real, integrando de forma transparente a experimentação nas atividades diárias de trabalho (Zhang, Calabrese, Ding, Liu, \& Zhang, 2017).

Hoehle e Venkatesh (2015) chamam os aplicativos móveis de softwares independentes, pois sua usabilidade não precisa de ligação com o computador ou outro equipamento e não interfere no funcionamento de outros programas do celular, além de serem elaborados para funcionar conectados à internet ou não.

Esses aplicativos permitem que os usuários acessem uma variedade de serviços e recursos sem a necessidade de um navegador web, ou seja, sem navegar na internet (Tan et al., 2017). Ademais, possibilitam que dispositivos inteligentes (smartphones) disponibilizem serviços móveis específicos, como informação, acesso a e-mail, entretenimento e facilidades profissionais (Rivera et al., 2016).

Procurar informações, realizar transações financeiras, executar atividades corporativas, expor opiniões ou conselhos relacionados a determinados problemas são ações que podem ser mais eficientes e rápidas, tendo um efeito mais apropriado por meio de alguma aplicação móvel (Noor et al., 2017).

Em vista disso, o uso de novas tecnologias, no caso dos aplicativos móveis, tem agregado valor ao turismo no sentido de ter a sua aplicabilidade voltada para serviços e/ou produtos turísticos, inserindo processos inovadores no desenvolvimento local/regional da atividade.

A inserção de aplicativos no turismo é enriquecedora no setor de planejamento e gestão por ter todas as informações, planos de ação, regimentos, normas, procedimentos, relatórios, estatísticas, dentre outras funcionalidades, na "palma da mão", permitindo acesso de qualquer lugar.

0 uso da tecnologia também pode aumentar a eficácia da gestão, a produtividade e a rentabilidade das organizações de turismo, desde que a atitude gerencial seja adaptada ao novo ambiente de negócios e aproveite as novas oportunidades (Buhalis, 1998).

Muitos destinos turísticos já perceberam a importância da tecnologia móvel aplicada ao desenvolvimento estratégico da atividade, principalmente quando está ligada à transparência de informações, acesso rápido a documentos, comunicação entre várias empresas, formação de experiências turísticas e interatividade. 
Isso mostra que gestores de turismo, sejam eles públicos ou privados, estão dispostos a aderir à tecnologia móvel para agregar valor e aumentar a posição competitiva do produto ou destinação (Rivera et al., 2016).

A aplicação móvel invadiu vários campos, inclusive comércio, saúde, marketing, transporte, finanças, serviços e entretenimento (Noor et al., 2017). A citação dos campos de serviços e entretenimento faz lembrar a área de turismo, que já possui muitos aplicativos desenvolvidos para auxiliar o turista antes e durante sua estada em algum lugar. Mas, além de ser vantajoso para demanda, também o é para a oferta, que pode inseri-lo em suas atividades de planejamento, gestão, estratégias, controle, operações e avaliação, tornando-se uma ferramenta de trabalho apropriada ao desenvolvimento da atividade.

0 uso estratégico da tecnologia possibilita a realização de processos intraorganizacionais, apoiando certo nível de integração entre várias funções dentro das organizações. 0 objetivo é aumentar a eficiência e a produtividade, bem como melhorar o gerenciamento estratégico e operacional da empresa. Exemplos em uma organização de turismo incluem sistemas de planejamento, de gestão, controle operacional, funções de gerenciamento, pesquisa de demanda, planos de ação, relatórios, entre outros (Buhalis, 1998).

Várias aplicações úteis estão disponíveis no turismo, apoiando funções inter e intraorganizacionais. Isso muitas vezes fortalece os esforços conjuntos de gestores de empresas diferentes em busca de um objetivo comum, bem como a realização da integração horizontal, vertical ou diagonal de todos os envolvidos no desenvolvimento do turismo (Buhalis, 1998).

Em suma, a tecnologia pode ajudar as novas formas de gestão a alcançar vantagens competitivas, aperfeiçoar o desempenho da produção, aumentar a circulação da informação e potencializar seu crescimento com novos negócios.

\section{METODOLOGIA}

A escolha de estudar as temáticas tecnologia e governança turística está associada de forma direta à inovação e novos olhares para o desenvolvimento do turismo em uma dada destinação, além de apresentar a intervenção das transformações que as tecnologias móveis ocasionam na perspectiva de uso por gestores públicos e prestadores de serviços turísticos.

Assim sendo, acredita-se que as características da pesquisa qualitativa se apresentam mais apropriadas para iniciar a metodologia deste trabalho, associadas ao levantamento de dados a respeito do uso das tecnologias móveis e seu envolvimento na execução de atividades turísticas, bem como ao entendimento e análise de determinados comportamentos, opiniões e perspectivas da utilização dessa ferramenta.

Segundo Godoy (1995), a pesquisa qualitativa tem um reconhecido lugar entre as várias possibilidades de estudar os fenômenos que envolvem os seres humanos, suas atitudes e relações com os diversos ambientes e o manuseio de instrumentos de trabalho. Esse entendimento ressalta que a pesquisa qualitativa busca compreender ações, experiências e comportamentos das pessoas diante da sociedade, sendo o elemento humano fundamental para sua finalização (Gil, 2008).

As técnicas utilizadas para desenvolver a pesquisa foram as seguintes: pesquisa bibliográfica e de campo (in loco). Nesta última foi utilizado o formulário como 
instrumento de coleta de dados para auxiliar nos resultados e discussões acerca do uso das tecnologias móveis por gestores públicos e fornecedores turísticos.

Segundo Marconi e Lakatos (2003), o formulário é um dos recursos principais para a pesquisa social, em que o procedimento de coleta de dados consiste em conseguir informações diretamente do entrevistado, ou seja, sua característica primordial é o contato face a face entre pesquisador e informante, além do roteiro de perguntas a ser preenchido pelo entrevistador, no ato da entrevista.

A pesquisa bibliográfica, também chamada de pesquisa de fontes secundárias, compreende toda referência teórica já publicada em relação ao tema estudado. Por meio dela, o pesquisador tem contato direto com o que foi escrito, dito ou filmado sobre determinado assunto (Marconi \& Lakatos, 2003; Gil, 2008). Está fundamentada em livros, trabalhos acadêmicos (dissertações e teses), artigos científicos e referências em meio eletrônico, principalmente no portal de periódicos da Coordenação de Aperfeiçoamento de Pessoal do Nível Superior (Capes). Destacam-se os seguintes autores que discutem sobre gestão e governança turística: Rhodes (1996); Svensson, Nordin e Flagestad (2005); Baggio, Scott e Cooper (2010); Cooper, Hall e Trigo (2011); Brito (2014); Beritelli e Bieger (2014); Tomio e Schmidt (2014); González (2014); Trentin (2016).

Outra temática abordada na pesquisa é a tecnologia no turismo, especificamente de dispositivos mobile, na governança e gestão turísticas. Sobre o assunto, as discussões ainda são incipientes, sendo este trabalho uma contribuição acadêmica para juntar-se aos seguintes autores: Dickinson et al. (2014); Hoehle e Venkatesh (2015); Rivera et al. (2016); Ramos et al. (2017); Noor et al. (2017); Tan et al. (2017); Xiang (2017) e Zhang et al. (2017).

A pesquisa de campo foi realizada em Aracaju, no período de novembro de 2017 a abril de 2018 (seis meses), deixando os profissionais à vontade, com bastante tempo e atenção para responder o formulário, mesmo a aplicação sendo em período de alta temporada, com início das férias de final de ano e feriados prolongados como Réveillon, Carnaval, Páscoa e Tiradentes.

Para definir a amostra principal, foram utilizados os dados disponíveis no Cadastur ${ }^{1}$ por meio dos relatórios do último trimestre de 2017, para quantificar o total dos meios de hospedagem e das agências de viagens de Aracaju e assim justificar a amostra para realização do formulário da pesquisa (Tabela 1).

Tabela 1 - Total de meios de hospedagens e agências de viagens em Sergipe e Aracaju

\begin{tabular}{|l|c|c|c|}
\hline \multicolumn{1}{|c|}{ Atividade } & Sergipe & Aracaju & \% \\
\hline Meio de hospedagem & A & B & B*100/A \\
\hline Agência de viagem & 38 & 26 & 68,4 \\
\hline
\end{tabular}

Fonte - Adaptado de Ministério do Turismo (2016)

De acordo com a Tabela 1, a quantidade dos dois tipos prestadores de serviços turísticos é significativa na capital sergipana principalmente por se tratar de um

1. Cadastro obrigatório de pessoas físicas e jurídicas que atuam no turismo de acordo com as leis 8.623/1993 e 11.771/2008. Executado pelo Ministério do Turismo (MTur) juntamente com os órgãos oficiais de turismo nos 26 estados do Brasil e no Distrito Federal, com o objetivo de propiciar a organização, a formalização e a legalização dos prestadores de serviços turísticos no Brasil, por meio de cadastro de empresas e profissionais do setor (Ministério do Turismo, 2016). 
destino indutor, aquele que possui infraestrutura básica e turística com oferta de atrativos, caracterizando-se como núcleo receptor e/ou distribuidor de fluxos turísticos. Ou seja, é um destino capaz de atrair e/ou distribuir significativo número de turistas para seu entorno, em busca de dinamizar a economia do território em que estão inseridos (Barbosa, 2008), onde está concentrada a maior parte de infraestrutura e equipamentos para o turismo, mais um motivo que justifica realizar a pesquisa de campo na capital, devido à representatividade de prestadores de serviços.

Os demais prestadores de serviço inclusos na amostra são dez locadoras de veículos em funcionamento encontradas no aeroporto Santa Maria e na internet, definidos aleatoriamente, e os gestores públicos do turismo, sendo um representante da esfera municipal e outro da estadual.

De acordo com esses quantitativos, a população total da pesquisa é de 191 prestadores de serviços turísticos, mas para calcular com exatidão a quantidade de formulários que seriam aplicados, recorreu-se ao software Raosoft (2004) com uma margem de erro de 7\% e nível de confiança de $90 \%$, totalizando 81 formulários de pesquisa para gestores públicos e prestadores de serviços das diversas atividades do turismo (Tabela 2).

Tabela 2 - Número de formulários aplicados em Aracaju

\begin{tabular}{|l|c|c|}
\hline \multicolumn{1}{|c|}{ Atividade } & Números absolutos & \% \\
\hline Meio de hospedagem & 19 & 23,4 \\
\hline Agência de viagem & 50 & 61,8 \\
\hline Locadora de veículo & 10 & 12,4 \\
\hline Secretaria de Turismo do estado & 1 & 1,2 \\
\hline Secretaria de Turismo do município & 1 & 1,2 \\
\hline TOTAL & 81 & 100 \\
\hline
\end{tabular}

Fonte - Elaborada pelos autores, 2018

Os formulários foram elaborados com cinco perguntas objetivas - de maneira a facilitar seu preenchimento para posterior compilação e análise dos dados -, cujos conteúdos versaram sobre uso e influência das tecnologias móveis para a gestão e desenvolvimento de atividades na empresa, a funcionalidade de seu website para as tecnologias móveis e as influências das redes sociais (Facebook e Instagram) na gestão.

\section{RESULTADOS E DISCUSSÃO}

Após compilação dos dados, a pesquisa revelou que 100\% dos entrevistados utilizam alguma tecnologia móvel para a gestão e desenvolvimento de atividades no ambiente de trabalho para uso corporativo. Ademais, $86 \%$ deles utilizam o smartphone e $14 \%$ o tablet para esta finalidade. Este comportamento atesta diretamente uma relação com a teoria abordada, visto que a tecnologia móvel está em constante crescimento para uso cada vez maior no dia a dia, tanto para atividades pessoais quanto para profissionais. 
Os entrevistados, ao responderem esse questionamento, informaram que a ferramenta é de uso essencial para tomadas de decisão, com respostas e/ou soluções imediatas, além de ajudar no acesso rápido a qualquer informação.

Esses instrumentos tecnológicos foram apontados como mecanismos facilitadores, práticos e inovadores, cujo acesso à internet tem a possibilidade de esclarecer dúvidas, verificar informações na rede de alcance mundial (www), bem como utilizar aplicativos móveis que auxiliam também nas atividades. Percebese que a proporção de uso de smartphones é muito maior devido às inúmeras funcionalidades que eles possuem reunidas em um único aparelho.

Com o advento da internet foi possível desenvolver o comércio eletrônico, que hoje é muito forte em todo o mundo, além do sistema bancário/financeiro, possibilitando realizar toda e qualquer atividade mediante cliques, de modo rápido, com baixo custo e bastante conforto, sem deslocamentos.

Questionados sobre a gestão do website da empresa, todos os entrevistados informaram que é uma plataforma muito importante para apresentar ao mercado/ aos turistas informações completas sobre a prestação de serviço e localização, além de ser uma forma de transmitir segurança, visto que estará disponível para acesso mundial na rede. Mas, de acordo com os entrevistados, muitos não atentaram a importância de adaptar o website para o acesso através de dispositivos móveis, como o celular, e 59 pessoas, equivalente a $73 \%$, informaram que não possuem website adaptado para visualização pelo celular. Os demais $27 \%$ apresentam esta preocupação porque sabem do avanço da tecnologia por meio dos equipamentos móveis, além de tornar seu site totalmente adaptado para que as pessoas que acessem tenham facilidade em realizar algum compra, enviar alguma dúvida ou compartilhar/divulgar informações com outras pessoas pelas redes sociais.

Mesmo sabendo da importância das tecnologias móveis no mundo atual, onde as pessoas estão cada vez mais pesquisando e utilizando o celular para buscar informações em qualquer momento e em qualquer lugar, as empresas não disponibilizam seu produto ou serviço através de dispositivos móveis. E para ter uma visibilidade maior do seu negócio, bem como da promoção e comercialização da sua atividade, essa ação deve ser incluída na gestão da empresa, possibilitando chegar ainda mais rápido ao público-alvo.

Hoje o potencial cliente está totalmente voltado para uso da tecnologia móvel. Assim, ao utilizar seu smartphone ou tablet para pesquisar algum destino turístico ou seu equipamento específico - como hotel, pousada, restaurante ou parque - para saber mais informações e não conseguir visualizar devido a problemas do site, possivelmente desistirá. Desse modo, aquela destinação poderá perder a sua demanda, visto que as empresas da oferta turística não possuem a preocupação de acompanhar a evolução e modernização da tecnologia para chegar aos clientes de todas as formas, inclusive pelos dispositivos móveis.

A tecnologia móvel oportunizou avanços em vários campos da economia, política, cultura, meio ambiente, lazer, negócios e comércio de modo geral, com a possibilidade de inseri-los nas redes sociais de comunicação, como Facebook, Twitter, Instagram e LinkedIn, ferramentas que estão presentes no dia a dia da vida pessoal e profissional de bilhões de pessoas no mundo.

No que diz respeito às redes sociais (Facebook e Instagram), 85\% dos entrevistados possuem uma ou as duas formas para manter uma relação com seu cliente, e 15\%, equivalente a 12 entrevistados, informaram não ter redes sociais, visto que 
ainda são microempreendedores individuais (MEI) com um quantitativo reduzido de mão de obra para administrar essas ferramentas, mas afirmaram ter como meta de gestão a implantação delas no futuro próximo. Este quantitativo mínimo possui a consciência da importância das redes sociais para o desenvolvimento e manutenção dos seus negócios, pois são ferramentas que podem fornecer dados estatísticos fundamentais para o planejamento e execução de estratégias de alcance do seu cliente.

Como consequência da resposta anterior, outro questionamento realizado foi a motivação de ter a empresa nas redes sociais. Para os 69 entrevistados que possuem redes sociais (Facebook, Instagram), 45\% responderam ser devido à promoção e comercialização do produto ou serviço ofertado, cuja divulgação é fácil e tem custo reduzido, ou seja, resume-se em uma estratégia de venda e ferramenta econômica. Enquanto 38\% afirmaram que o motivo principal é a interação com o cliente, a possibilidade de o cliente/turista acompanhar todas as atualizações da empresa, inclusive em tempo real com os stories do Instagram, com realização de campanhas promocionais, sorteios para conquistar mais clientes (seguidores) e divulgação de informações importantes, que podem ser visualizadas pelo celular (Gráfico 1).

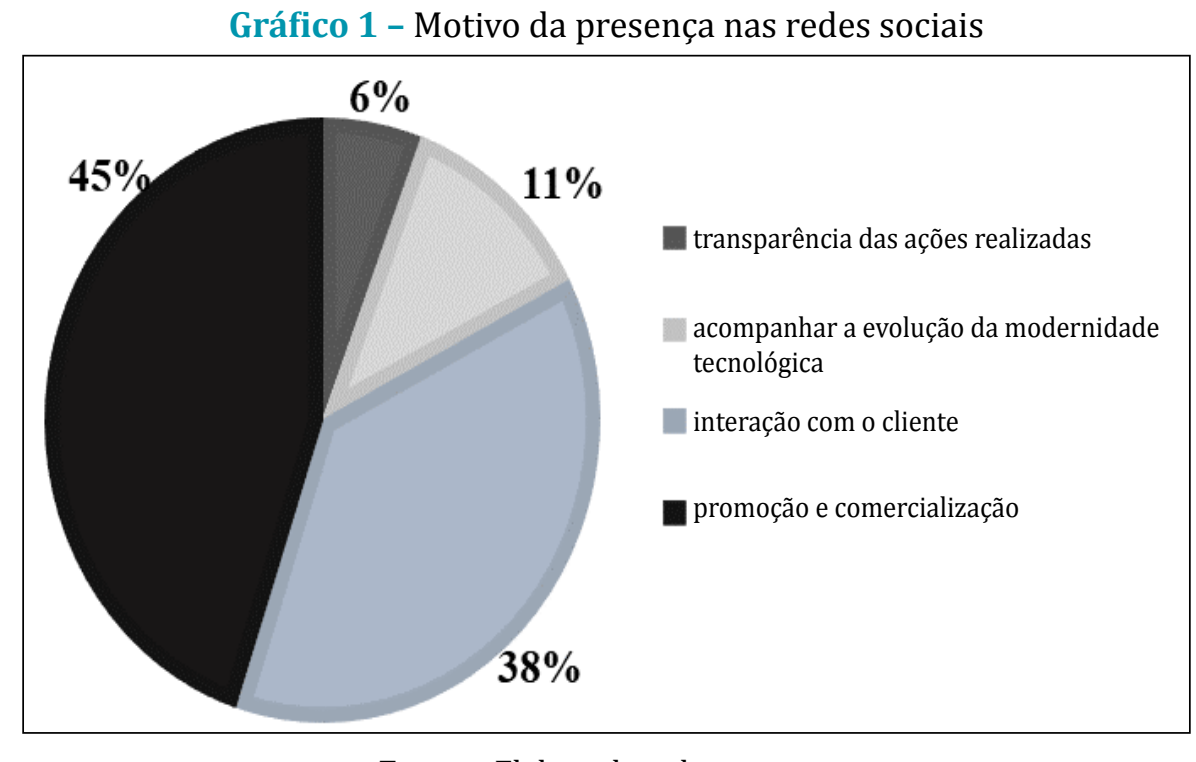

Fonte - Elaborado pelos autores

Os demais motivos estão explanados no Gráfico 1. Uma pequena parte informou que, para não ficar de fora do mundo inovador das redes sociais, dispõe de uma equipe para alimentar o perfil com informações sobre a empresa, mas sem muita interação com seu cliente, para dividir conhecimento sobre as atividades que a organização realiza.

Uma das respostas - $6 \%$ dos entrevistados - descreve bem o perfil dos gestores públicos, ao utilizar as redes sociais motivados a mostrar as ações que desenvolvem para o cidadão. Como as redes sociais possuem muitos usuários, a gestão pública, para ficar mais próxima dos seus eleitores, aderiu a elas e busca intensificar seu uso para também coletar dos próprios cidadãos um feedback de suas ações, além de sugestões para continuar desenvolvendo um trabalho de melhorias para sociedade.

Com o avanço e fortalecimento das redes sociais como ferramenta de comunicação, informação, venda e interação com a sociedade e/ou cliente, os gestores públicos municipais e estaduais utilizam-nas para divulgar os resultados de 
investimentos em infraestrutura básica e turística, saneamento básico e ambiental, manutenção do bem público, inaugurações, entre outras ações que favoreçam a administração pública e beneficiem seus cidadãos, de modo aberto e transparente, com o uso da tecnologia para essas finalidades.

A última pergunta do questionário foi essencial para responder o objetivo desse estudo, uma vez que $82 \%$ informaram que as novas tecnologias móveis são ferramentas relevantes que facilitam e agilizam as tomadas de decisão e estratégias de atuação para atingir o turista e resolver necessidades pessoais e empresariais do dia a dia (Gráfico 2).

Gráfico 2 - Influência das tecnologias móveis na gestão

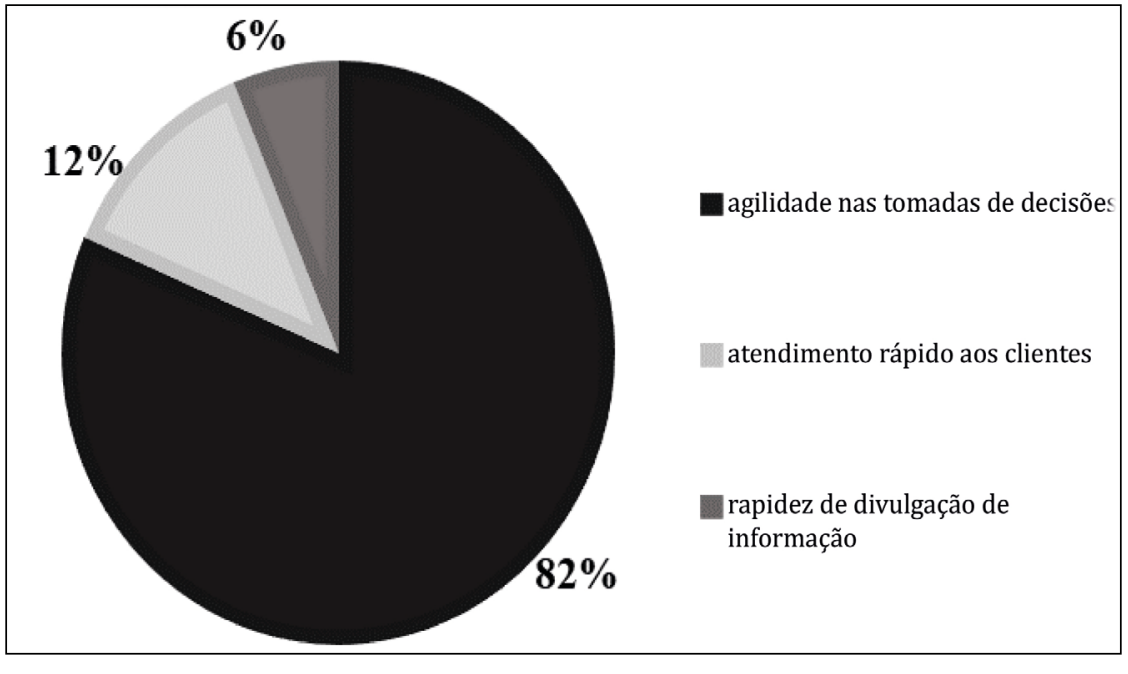

Fonte - Elaborado pelos autores

A outra influência é o atendimento rápido aos clientes, resposta dada principalmente por agências de viagens, com $12 \%$, por justificar que o cliente, quando envia um e-mail ou uma mensagem por rede social, deseja receber retorno o quanto antes. Para não perdê-lo, ter essa facilidade da tecnologia móvel é uma oportunidade de aumentar a produtividade e a fidelização, além de aprimorar a gestão da empresa.

Ainda de acordo com o Gráfico 2, um quantitativo menor, de 6\%, equivalente a cinco empresas, respondeu que faz uso de novas tecnologias móveis devido à rapidez de divulgação da informação, sobretudo associando ao fator da internet, que influencia e auxilia o mais rápido possível as atividades internas e externas da empresa.

\section{CONSIDERAÇÕES FINAIS}

A intervenção que as tecnologias móveis ocasionam na perspectiva de uso de gestores públicos e prestadores de serviços turísticos proporciona modificações no formato de gestão das atividades, influenciando, enquanto ferramentas intermediárias e relevantes, nas tomadas de decisão, no atendimento rápido e ágil aos clientes, na velocidade de disseminação de informações em tempo real e nas estratégias de atuação referentes ao uso das redes sociais para atingir o turista.

Sugere-se apresentar os resultados deste estudo aos demais componentes do trade turístico, bem como aos próprios entrevistados para que possam perceber e utilizar como exemplo o nível de influência que as tecnologias móveis exercem 
para uma gestão bem-sucedida das atividades na empresa e em prol do desenvolvimento turístico, dando mais visibilidade a produtos e serviços que ainda não são ofertados para atingir o cliente/turista, "antenado" com novos padrões de referência sobre o uso avançado das tecnologias móveis.

A relação da tecnologia com a governança deve ser praticada, transformando-se em realidade e possibilitando uma gestão das empresas mais eficiente, eficaz, cooperada e competitiva mediante valorização e participação ativa de todos os profissionais afetados, envolvidos com o desenvolvimento da atividade turística.

Os resultados obtidos na pesquisa de campo permitem concluir, através de uma amostragem representativa, que existe influência da tecnologia - tecnologias móveis - na gestão das atividades dos prestadores de serviços do turismo em Aracaju. Igualmente, o resultado geral dos formulários mostra o quanto a tecnologia, principalmente a móvel, está inserida nas atividades dos prestadores de serviços do turismo, bem como na gestão municipal de Aracaju e na gestão estadual de Sergipe.

\section{REFERÊNCIAS}

Baggio, R., Scott, N., \& Cooper, C. (2010). Improving tourism destination governance: a complexity science approach. Tourism Review, 65(4), 51-60. doi: $10.1108 / 16605371011093863$

Barbosa, L. G. M. (Org.). (2008). Estudo de competitividade dos 65 destinos indutores do desenvolvimento turístico regional: relatório Brasil. Brasília, DF: Autor. Recuperado de https://bit.ly/2UZBhNe

Beritelli, P., \& Bieger, T. B. (2014). From destination governance to destination leadership - defining and exploring the significance with the help of a systemic perspective. Tourism Review, 69(1), 25-46. doi: 10.1108/TR-07- 2013-0043

Bolsoni, W. (2004). Tecnologia aplicada à Indústria do Turismo. In: B. H. G. Lage (Ed.), Turismo, hotelaria \& lazer. São Paulo: Atlas.

Ministério do Turismo. (2016). Prestadores de serviços turísticos / CADASTUR. Recuperado de http://dados.turismo.gov.br/cadastur

Brito, A. S. (2014). Governança em território turístico: uma análise comparativa entre a Costa das Baleias (BA) e o município de Bento Gonçalves (RS). Dissertação de Mestrado, Universidade Federal da Bahia, Salvador.

Buhalis, D. (1998). Strategic use of information technologies in the tourism industry. Tourism Management, 19(5), 409-421.

Cooper, C., Hall, M., \& Trigo, L. G. G. (2011). Turismo contemporâneo. Rio de Janeiro: Elsevier.

Dickinson, J. E., Ghali, K., Cherrett, T., Speed, C., Davies, N., \& Norgate, S. (2014). Tourism and the smartphone app: capabilities, emerging practice and scope in the travel domain. Current Issues in Tourism, 17(1), 84-101.

Gil, A. C. (2008). Métodos e técnicas de pesquisa social. São Paulo: Atlas.

Godoy, A. S. (1995). Introdução à pesquisa qualitativa e suas possibilidades. Revista de Administração de Empresas, 35(2), 57-63. doi: 10.1590/S0034-75901995000200008

González, M. V. (2014). Gobernanza turística: ¿Políticas públicas innovadoras o retórica banal? Caderno Virtual de Turismo, 14(1), 9-22. Recuperado de https://bit.ly/2HwwSh0

Hassan, H. (2011). Tecnologias de informação e turismo: e-tourism. Dissertação de Mestrado, Universidade de Coimbra, Coimbra. Recuperado de https://bit.ly/2MaILx8 
Hoehle, H., \&Venkatesh, V. (2015). Mobile application usability: conceptualization and instrument development. MIS Quarterly, 39(2), 435-472. Recuperado de https://bit.ly/2VTOyM1

Marconi, M. A., \& Lakatos, E. M. (2003). Fundamentos de metodologia científica. São Paulo: Atlas.

Martins, C., Fiates, G. G. S., \& Pinto, A. L. (2016). A relação entre os clusters de turismo e tecnologia e seus impactos para o desenvolvimento local: um estudo bibliométrico da produção científica. Revista Brasileira de Pesquisa em Turismo, 10(1), 65-88. Recuperado de https://rbtur.org.br/rbtur/article /view/907

Nascimento, I., Maia, A. F., \& Dias, P. O. O. (2012). A experiência como produto turístico: a emoção e a sensação do novo e diferente. Revista Turismo: Estudos e Práticas, 2(1), 142-159.

Noor, N. M., Mahmud, S. A., Wahidin, I. S., \& Arshad, S. R. (2017). Users readiness towards mobile application: a preliminary findings. Journal of Information System and Technology Management, 2(6), 55-61. Recuperado de https://bit.ly/2VTNt7g

Pedroso, R. F. (2012). A gestão turística face às novas tendências com aplicação nas áreas protegidas - estudo de caso no âmbito do turismo de natureza. Dissertação de Mestrado, Universidade Lusófona de Humanidades e Tecnologias, Lisboa. Recuperado de http://recil.grupolusofona.pt/handle/10437/5077

Ramos, A. S. M., Mendes Filho, L. A. M., \& Lobianco, M. M. L. (2017). Sistemas e tecnologia da informação no turismo: um enfoque gerencial. Curitiba: Prismas.

Raosoft. (2004). Sample size calculator. Recuperado de https://bit.ly/1FF94xn

Rhodes, R. A. W. (1996). The new governance: governing without government. Political Studies, 44(4), 652-667. doi: 10.1111 / j.1467-9248.1996.tb01747.x

Rivera, M., Croes, R., \& Zhong, Y. Y. (2016). Developing mobile services: a look at first time and repeat visitors in a small island destination. International Journal of Contemporary Hospitality Management, 28(12), 2721-2747. doi: 10.1108/ IJCHM-02-2015-0052

Roth, A. L., Wegner, D., Antunes, J. A. V., Jr., \& Padula, A. D. (2012). Diferenças e inter-relações dos conceitos de governança e gestão de redes horizontais de empresas: contribuições para o campo de estudos. Revista de Administração, 47(1), 112-123. doi: 10.5700/rausp1029

Svensson, B., Nordin, S., \& Flagestad, A. (2005). A governance perspective on destination development-exploring partnerships, clusters and innovation systems. Tourism Review, 60(2), 32-37. doi: 10.1108/eb058455

Tan, G. W.-H., Lee, V. H., Lin, B., \& Ooi, K.-B. (2017). Mobile applications in tourism: the future of the tourism industry? Industrial Management \& Data Systems, 117(3), 560-581. doi: 10.1108/IMDS-12-2015-0490

Tomio, M., \& Schmidt, C. M. (2014). Governança e ações coletivas no turismo regional: a experiência dos Empreendedores da Região Oeste do Paraná. Revista Turismo: Visão e Ação, 16(3), 710-739. doi: 10.14210/rtva.v16n3

Trentin, F. (2016). Governança turística em destinos brasileiros: comparação entre Armação dos Búzios/RJ, Paraty/RJ e Bonito/MS. PASOS. Revista de Turismo y Patrimonio Cultural, 14(3), 645-658. Recuperado de http://www.redalyc.org/html/881/88145925006

Xiang, Z. (2017). From digitization to the age of acceleration: on information technology and tourism. Tourism Management Perspectives, 25, 147-150. doi: 10.1016/j.tmp.2017.11.023

Zhang, J., Calabrese, C., Ding, J., Liu, M., \& Zhang, B. (2017). Advantages and challenges in using mobile apps for field experiments: A systematic review and a case study. Mobile Media \& Communication, 6(2), 179-196. doi: 10.1177/2050157917725550 


\section{CONTRIBUIÇÕES}

Leylane Meneses Martins: Definição do problema de pesquisa e objetivos; desenvolvimento da proposição teórica; realização da revisão bibliográfica e fundamentação teórica; escolha dos procedimentos metodológicos; coleta de dados; redação do manuscrito; e adequação do manuscrito às normas da RTA.

José Wellington Carvalho Vilar: Realização da revisão bibliográfica e fundamentação teórica; análise de dados; revisão crítica dos manuscritos; e redação do manuscrito. 